\title{
Predictors of early synchronized non-invasive ventilation failure for infants $<32$ weeks of gestational age with respiratory distress syndrome
}

\author{
Nesrin M. Handoka¹, Mona Azzam², Ayman Gobarah²
}

${ }^{1}$ Pediatrics Department, Faculty of Medicine, Port-Said University, Port-Said, Egypt ${ }^{2}$ Pediatrics Department, Faculty of Medicine, Suez Canal University, Ismailia, Egypt

Submitted: 17 March 2018

Accepted: 18 June 2018

Arch Med Sci 2019; 15 (3): 680-687

DOI: https://doi.org/10.5114/aoms.2019.83040

Copyright $\odot 2018$ Termedia \& Banach

\section{Abstract}

Introduction: The current trend in management of preterm neonates with respiratory distress syndrome is to attempt noninvasive ventilation (NIV) to avoid endotracheal intubation. However, failure of noninvasive ventilation may lead to increased morbidity and mortality. There is a scarcity of studies establishing predictors for the usefulness of NIV in this age group. Our aim here was to determine the predictors of NIV in preterm infants with respiratory distress syndrome (RDS) treated with synchronized nasal intermittent positive pressure ventilation (SNIPPV) for initial respiratory support.

Material and methods: We conducted a follow-up study on 85 infants $<32$ weeks of gestational age, and $<1500 \mathrm{~g}$ with RDS who received early SNIPPV. Perinatal history, physical characteristics, ventilatory settings, and arterial blood gas analysis results were collected. We recorded the failure rate and potential predictive factors of this failure.

Results: There were 12 (14.1\%) patients who had SNIPPV failure. The SNIPPV failure group had multiple significantly different characteristics compared to the successful SNIPPV group including gestation age, birth weight, grading of disease, severity of respiratory distress, antenatal steroid use and various ventilatory settings. Further multivariate analysis revealed only 3 predictors in our patients: grade of $\operatorname{RDS}(\mathrm{OR}=4.48, p=0.008)$, antenatal steroid use $(\mathrm{OR}=1.09, p=0.01)$ and mean airway pressure $(\mathrm{OR}=1.98, p=0.0001)$.

Conclusions: Failure of early NIV occurred in a small subset of our patients. Predictors of noninvasive ventilation failure may be a useful guide for decisions regarding intubation.

Key words: preterm infants, predictors, respiratory distress syndrome, synchronized nasal intermittent positive pressure ventilation failure.

\section{Introduction}

Respiratory distress syndrome (RDS) is a major cause of morbidity and mortality in preterm infants [1]. Studies using nasal ventilation as the first step, prior to surfactant administration, have been published [2]. Synchronized nasal intermittent positive pressure ventilation (SNIPPV) is a form of noninvasive ventilation during which patients are exposed intermittently to higher levels of airway pressure, along with nasal continuous positive airway pressure (NCPAP) through the same nasal device [3].

Non-invasive ventilation (NIV) is used in preterm infants with RDS soon after birth to reduce ventilator lung injury and bronchopulmonary

\author{
Corresponding author: \\ Mona Azzam MD, PhD \\ Pediatrics Department \\ Faculty of Medicine \\ Suez Canal University \\ 215 St 10 Al-Ballah District \\ L5M0C5 Ismailia, Egypt \\ Phone: +20 1008135502 \\ E-mail: mona.azzam@yahoo. \\ com
}


dysplasia (BPD) [4]. Moretti et al. [5] reported an association between application of SNIPPV and increased tidal and minute volumes when compared to NCPAP in the same infant. It has also been demonstrated that SNIPPV recruits collapsed alveoli, thereby increasing functional residual capacity and decreasing the need for mechanical ventilation (MV) [6].

Several explanations may account for the effectiveness of SNIPPV. One explanation by Kiciman et al. [7] is that thoracoabdominal motion asynchrony and flow resistance through the nasal prongs are decreased on SNIPPV, with improved stability of the chest wall and pulmonary mechanics. Addition of a peak inspiratory pressure (PIP) above positive end expiratory pressure (PEEP) by using SNIPPV could also increase flow delivery in the upper airway [8]. SNIPPV is postulated to increase the beneficial effects of NCPAP [9]. Aghai et al. [10] reported that infants receiving SNIPPV have decreased work of breathing, again emphasizing that thoracoabdominal synchronization with SNIPPV may account, in part, for its efficacy.

Non-invasive ventilation support has significantly changed RDS management in preterm infants. Further perspectives for neonatologists involve the assessment of failure in NIV. We designed this study to identify the predictors of non-invasive ventilation failure in preterm infants (GA $<32$ weeks) with RDS treated with SNIPPV as primary respiratory support.

\section{Material and methods}

A follow-up study was carried out in the neonatal intensive care unit (NICU) of El-Nasr Hospital, Port-Said, Egypt during the period from March 2015 to January 2017. It was approved by the Institutional Ethics Committee and informed consent was obtained from the parents of the participants. Brief counseling regarding early NIV for treatment of RDS, together with clarification of the aim and methodology, and the outcomes were included in the informed consent process.

A total of 160 neonates were assessed for eligibility, of which 85 were included and were treated with early SNIPPV (Figure 1).

Inclusion criteria: Preterm newborns with gestational age (GA) less than 32 weeks, and birth weight less than $1500 \mathrm{~g}$ suffering from RDS.

Exclusion criteria: Preterm newborns with hypoxic ischemic encephalopathy, nasopharyngeal pathology, or presence of cardiovascular instability. Apneic or severely depressed newborns requiring intubation after birth were excluded from the study and started on MV.

For all participants, a perinatal history was documented including antenatal steroid treatment, mode of delivery, gender, birth weight, and surfactant replacement. Assessment of gestational age was performed using the Ballard score and Apgar scores at 1 and 5 min were recorded. We used the Downes score for assessment of severity of respiratory distress [11] and grading of RDS was performed according to the X-ray findings [12].

Indications for SNIPPV were documented including blood gas analysis at time of initiation of SNIPPV. The criteria for initiation included $\mathrm{pH}$ $\leq 7.20, \mathrm{PaCO}_{2} \geq 65 \mathrm{~mm} \mathrm{Hg}, \mathrm{FiO}_{2} \geq 0.4$ to maintain arterial oxygen saturation $\left(\mathrm{SaO}_{2}\right)$ of $89 \%$ to $93 \%$. SNIPPV support was applied using the CONVIDIEN Ventilator System for Adults, Pediatrics and Neonates Model Puritan Bennett 840 , and was provided by a nasal interface, with short nasal prongs. Synchronization was obtained by means of an inspiratory flow sensor. The initial respiratory parameters were PEEP 6 to $8 \mathrm{~cm} \mathrm{H}_{2} \mathrm{O}$; PIP $15-25 \mathrm{~cm}$ $\mathrm{H}_{2} \mathrm{O}$; inspiratory time 0.3 to $0.4 \mathrm{~s}$; flow rate 6 to 10 l/min; and respiratory rate (RR) 30-40 breaths per minute and fraction of inspired oxygen $\left(\mathrm{FiO}_{2}\right)$ $21 \%$ to $60 \%$ adjusted to keep saturations at $89 \%$ to $93 \%$. The settings could be increased or decreased if needed to maintain the target blood gases.

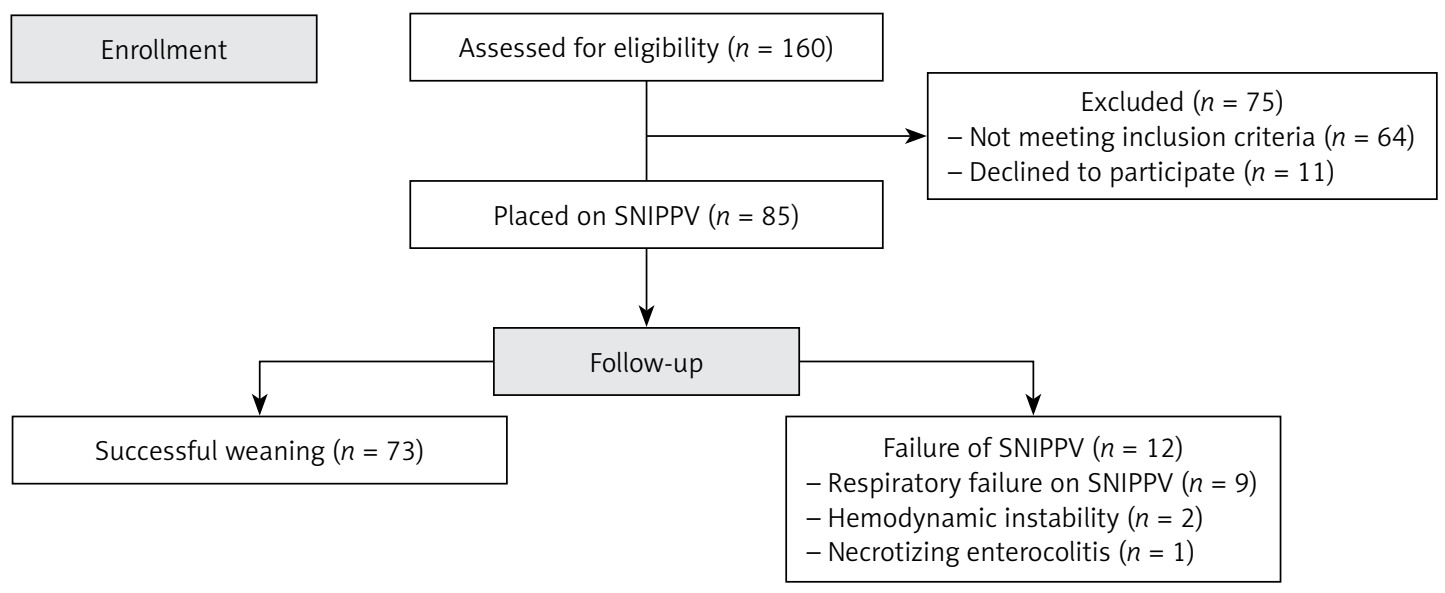

Figure 1. Flowchart of patient assessment for eligibility, exclusion and follow-up 
Ventilatory settings were recorded and the mean settings over the first $24 \mathrm{~h}$ of ventilation required to normalize blood gas and maintain an acceptable $\mathrm{O}_{2}$ saturation by pulse oximetry were calculated. Duration of SNIPPV, duration of oxygenation, and length of hospital stay were recorded for each participant.

Weaning from SNIPPV was performed with a reduction of $R R$ to 15 breaths per minute with a PIP of 10 to $15 \mathrm{~cm} \mathrm{H}_{2} \mathrm{O}$ and a PEEP of $4 \mathrm{~cm} \mathrm{H}_{2} \mathrm{O}$ and was stopped when infants showed no signs of respiratory distress with $\mathrm{FiO}_{2} \leq 0.30$.

Patients were monitored, and if they met criteria of SNIPPV failure support or if clinical deterioration occurred, MV was initiated. NIV failure was defined by the presence of the following (1) hypoxia ( $\mathrm{FiO}_{2}$ requirement $\geq 0.40$ ), (2) acidosis ( $\mathrm{pH}$ $\leq 7.20)$ and hypercarbia $\left(\mathrm{PCO}_{2} \geq 65 \mathrm{~mm} \mathrm{Hg}\right.$ ), and (3) apnea of 4 episodes/h or the need for bagmask ventilation, 2 times/h. We also considered necrotizing enterocolitis, bowel perforation, and hemodynamic instability as indications of NIV failure [13].

\section{Statistical analysis}

The Statistical Package for Social Sciences 21 (SPSS Inc., Chicago, IL, USA) was used for statistical analysis. Data were expressed as means \pm SD and percentage. Continuous data were analyzed by the Student $t$-test and Mann-Whitney test while categorical data were analyzed using the $\chi^{2}$ test and Fisher's exact test. Multivariate logistic regression was performed to assess predictors of NIV failure by calculating odds ratios (OR) and corresponding 95\% confidence intervals $(95 \% \mathrm{Cl})$. A $p<0.05$ was considered statistically significant.

\section{Results}

A total of 85 preterm neonates of less than 32 weeks' gestation received SNIPPV as primary respiratory support in our study, of which 12/85 patients (14.1\%) had SNIPPV failure, and 73/85 patients (85.9\%) were successfully ventilated non-invasively. Causes of failure included respiratory failure on SNIPPV in 9 patients, hemodynamic instability in 2 patients and necrotizing enterocolitis in 1 patient (Figure 1).

Comparison of characteristics between the SNIPPV with successful weaning versus the SNIPPV failure group demonstrated that the latter had a significantly lower gestational age and birth weight than the successful group. Maternal history of antenatal corticosteroids use, and Apgar scores at 5 min were also significantly associated with failure of SNIPPV.

Table I. Data comparison of the studied groups

\begin{tabular}{|c|c|c|c|}
\hline Variables & $\begin{array}{l}\text { Success group } \\
\quad(n=73)\end{array}$ & $\begin{array}{l}\text { Failure group } \\
\quad(n=12)\end{array}$ & $P$-value \\
\hline Gestational age [weeks] & $31.6 \pm 0.6$ & $31.1 \pm 0.3$ & $0.001^{a}$ \\
\hline Birth weight [g] & $1306 \pm 106$ & $1241 \pm 29$ & $0.001^{\mathrm{a}}$ \\
\hline Male/female & $29 / 44$ & $8 / 4$ & $0.117^{b}$ \\
\hline CS delivery (\%) & $56(88.9)$ & $10(83.3)$ & $0.63^{c}$ \\
\hline Antenatal corticosteroids use (\%) & $55(75.34)$ & $2(16.66)$ & $0.0001^{c}$ \\
\hline Surfactant use (\%) & $34(46.6)$ & $5(41.7)$ & $0.501^{c}$ \\
\hline Apgar at $1 \mathrm{~min}$ & $4.4 \pm 0.6$ & $4.1 \pm 0.5$ & $0.156^{\mathrm{a}}$ \\
\hline Apgar at $5 \mathrm{~min}$ & $6.92 \pm 0.7$ & $4.42 \pm 0.7$ & $0.0001^{\mathrm{a}}$ \\
\hline Severity of RD (\%) & $5.9 \pm 0.6$ & $6.8 \pm 0.8$ & $0.0001^{a}$ \\
\hline \multicolumn{4}{|l|}{ Grades of RDS (\%): } \\
\hline II & $63(86.3)$ & $1(8.3)$ & $0.0001^{c}$ \\
\hline III & $10(13.7)$ & $7(58.3)$ & \\
\hline IV & $0(0)$ & $4(33.3)$ & \\
\hline Duration of SNIPPV [days] & $6.23 \pm 1.4$ & $7.17 \pm 0.6$ & $0.021^{a}$ \\
\hline Duration of oxygenation [days] & $8.4 \pm 1.5$ & $10.5 \pm 1.3$ & $0.0001^{\mathrm{a}}$ \\
\hline Length of hospital stay [days] & $20.2 \pm 5$ & $32 \pm 5.4$ & $0.0001^{\mathrm{a}}$ \\
\hline
\end{tabular}

a Mann-Whitney test, ${ }^{b} \chi^{2}$ test, 'Fisher's test. CS - cesarean section, RD - respiratory distress, RDS - respiratory distress syndrome, SNIPPV - synchronized nasal intermittent positive pressure ventilation. 
Table II. Ventilator and arterial blood gas parameters of studied groups

\begin{tabular}{|c|c|c|c|c|c|}
\hline Parameter & & $\begin{array}{l}\text { Success group } \\
\quad(n=73)\end{array}$ & $\begin{array}{l}\text { Failure group } \\
\quad(n=12)\end{array}$ & Test value & $P$-value ${ }^{\mathrm{a}}$ \\
\hline \multirow[t]{3}{*}{$\mathrm{FiO}_{2}$} & Mean \pm SD & $28.7 \pm 2.3$ & $44.6 \pm 0.9$ & 2701 & 0.001 \\
\hline & Range & $24-35$ & $44-46$ & & \\
\hline & Median & 30 & 44 & & \\
\hline \multirow[t]{3}{*}{ PIP } & Mean \pm SD & $15.1 \pm 1$ & $17.8 \pm 1$ & 2739.5 & 0.001 \\
\hline & Range & $14-19$ & $16-19$ & & \\
\hline & Median & 15 & 18 & & \\
\hline \multirow[t]{3}{*}{ PEEP } & Mean \pm SD & $4.9 \pm 0.7$ & $6 \pm 0.7$ & 2836 & 0.001 \\
\hline & Range & $4-6$ & $5-7$ & & \\
\hline & Median & 5 & 6 & & \\
\hline \multirow[t]{3}{*}{$\mathrm{TI}$} & Mean \pm SD & $0.35 \pm 0.04$ & $0.4 \pm 0.04$ & 346 & 0.248 \\
\hline & Range & $0.3-0.44$ & $0.32-0.43$ & & \\
\hline & Median & 0.33 & 0.35 & & \\
\hline \multirow[t]{3}{*}{ RR } & Mean \pm SD & $27.1 \pm 2.7$ & $27.3 \pm 4.8$ & 380 & 0.457 \\
\hline & Range & $24-32$ & $24-34$ & & \\
\hline & Median & 26 & 24 & & \\
\hline \multirow[t]{3}{*}{ MAP } & Mean \pm SD & $6.3 \pm 0.5$ & $7.2 \pm 0.9$ & 2891 & 0.001 \\
\hline & Range & $5-7$ & $6-8$ & & \\
\hline & Median & 6 & 7.6 & & \\
\hline \multirow[t]{3}{*}{ Flow } & Mean \pm SD & $6.6 \pm 0.6$ & $6.9 \pm 0.7$ & 316.5 & 0.092 \\
\hline & Range & $6-8$ & $6-8$ & & \\
\hline & Median & 6 & 7 & & \\
\hline \multirow[t]{3}{*}{$\mathrm{PH}$} & Mean \pm SD & $7.21 \pm 0.04$ & $7.2 \pm 0.02$ & 298.5 & 0.073 \\
\hline & Range & $7.11-7.31$ & $7.18-7.24$ & & \\
\hline & Median & 7.21 & 7.19 & & \\
\hline \multirow[t]{3}{*}{$\mathrm{PaCO}_{2}$} & Mean \pm SD & $58.3 \pm 3$ & $60.8 \pm 2$ & 300 & 0.076 \\
\hline & Range & $50-62$ & $60-65$ & & \\
\hline & Median & 59 & 60 & & \\
\hline \multirow[t]{3}{*}{$\mathrm{PaO}_{2}$} & Mean \pm SD & $76.9 \pm 5.6$ & $72.1 \pm 4.5$ & 267 & 0.028 \\
\hline & Range & $70-86$ & $60-75$ & & \\
\hline & Median & 80 & 75 & & \\
\hline \multirow[t]{3}{*}{$\mathrm{StO}_{2}$} & Mean \pm SD & $88.4 \pm 1.1$ & $86.8 \pm 2.4$ & 288 & 0.049 \\
\hline & Range & $85-94$ & $85-90$ & & \\
\hline & Median & 88 & 85.5 & & \\
\hline \multirow[t]{3}{*}{ Bicarbonate } & Mean \pm SD & $19.8 \pm 1$ & $19 \pm 1.5$ & 320 & 0.115 \\
\hline & Range & $17-22$ & $15-21$ & & \\
\hline & Median & 20 & 19 & & \\
\hline
\end{tabular}

a Mann-Whitney test. FiO - fraction of inspired oxygen, PIP - peak inspiratory pressure, PEEP - positive end-expiratory pressure, TI inspiration time, $R R$-respiratory rate, $M A P$ - mean airway pressure, $\mathrm{pH}$ - potential of hydrogen, $\mathrm{PaCO}_{2}$ - partial pressure of carbon dioxide, $\mathrm{PO}_{2}$ - partial pressure of oxygen, $\mathrm{StO}_{2}$ - oxygen saturation. 
Preterm infants with SNIPPV failure had more severe respiratory distress according to Downes' criteria than the successful group, and also had higher grades of RDS with a statistically significant difference.

In addition, there were significant associations between longer duration of ventilation, duration of oxygenation requirement and hospital stay and SNIPPV failure. However, gender, mode of delivery, surfactant use, and Apgar score at $1 \mathrm{~min}$ were not significantly different between the successful SNIPPV group and the SNIPPV failure group (Table I).

As regards ventilatory settings, infants in the failed SNIPPV group had higher pressures (PIP, PEEP, MAP) than infants in the success group. Fur- thermore, the failed SNIPPV group had a lower arterial $\mathrm{PaO}_{2}$, and a higher $\mathrm{FiO}_{2}$ compared to the success group (Table II).

Using multivariate logistic regression, we found that antenatal corticosteroid, grade of RDS, and MAP were more valuable for predicting NIV failure (Table III).

\section{Discussion}

The aim of the management of RDS is to provide interventions that maximize survival whilst minimizing potential adverse effects, including the risk of BPD. Noninvasive ventilation is increasingly used in preterm infants to reduce complications that occur with invasive ventilation [14].

Table III. Predictors of non-invasive ventilation failure of studied groups

\begin{tabular}{|c|c|c|c|c|}
\hline \multirow[t]{2}{*}{ Independent variables } & \multirow[t]{2}{*}{ OR } & \multicolumn{2}{|c|}{$95 \% \mathrm{Cl}$ OR } & \multirow[t]{2}{*}{$P$-value } \\
\hline & & Lower & Upper & \\
\hline Gestational age & 0.058 & 0.003 & 0.074 & 0.067 \\
\hline Birth weight & 0.055 & 0 & 0.0001 & 0.141 \\
\hline Gender & 0.012 & 0.056 & 0.128 & 0.081 \\
\hline Mode of delivery & 0.028 & 0.017 & 0.081 & 0.199 \\
\hline Surfactant & 0.056 & 0.007 & 0.09 & 0.088 \\
\hline Antenatal corticosteroid & 1.09 & 1.018 & 1.122 & $0.01^{*}$ \\
\hline Apgar at $1 \mathrm{~min}$ & 0.006 & -0.027 & 0.035 & 0.799 \\
\hline Apgar at $5 \mathrm{~min}$ & 0.141 & 0.027 & 0.064 & 0.076 \\
\hline Severity of RD & 0.048 & -0.057 & 0.009 & 0.15 \\
\hline Grade of RDS & 4.480 & 2.196 & 7.805 & $0.008^{*}$ \\
\hline Duration of SNIPPV & 0.071 & 0.002 & 0.046 & 0.069 \\
\hline $\mathrm{FiO}_{2}$ & 0.05 & 0 & 0.009 & 0.065 \\
\hline PIP & 0.003 & 0.02 & 0.032 & 0.922 \\
\hline PEEP & 0.071 & 0.004 & 0.065 & 0.06 \\
\hline $\mathrm{Tl}$ & 0.021 & 0.006 & 0.678 & 0.399 \\
\hline $\mathrm{RR}$ & 0.98 & 0.802 & 1.198 & 0.847 \\
\hline MAP & 1.98 & 0.098 & 2.736 & $0.0001^{*}$ \\
\hline Flow & 0.014 & 0.028 & 0.102 & 0.061 \\
\hline $\mathrm{PH}$ & 0.041 & 0.006 & 0.881 & 0.092 \\
\hline $\mathrm{PaCO}_{2}$ & 0.015 & 0.008 & 0.024 & 0.544 \\
\hline $\mathrm{PaO}_{2}$ & 0.004 & 0.002 & 0.004 & 0.87 \\
\hline $\mathrm{StO}_{2}$ & 0.038 & 0.004 & 0.053 & 0.173 \\
\hline Bicarbonate & 0.053 & 0.001 & 0.035 & 0.065 \\
\hline
\end{tabular}

${ }^{d}$ Multivariate logistic regression. RD - respiratory distress, RDS - respiratory distress syndrome, SNIPPV - synchronized nasal intermittent positive pressure ventilation, $\mathrm{FiO}_{2}$ - fraction of inspired oxygen, PIP - peak inspiratory pressure, PEEP - positive end-expiratory pressure, $\mathrm{TI}$ - inspiration time, $\mathrm{RR}$ - respiratory rate, MAP - mean airway pressure, $\mathrm{pH}$ - potential of hydrogen, $\mathrm{PaCO} \mathrm{C}_{2}-$ partial pressure of carbon dioxide, $\mathrm{PO}_{2}$-partial pressure of oxygen, $\mathrm{StO}_{2}$ - oxygen saturation. 
Predictors of noninvasive ventilation failure can play a pivotal role in preventing clinical deterioration. We aimed to determine the predictors of early noninvasive ventilation failure for preterm infants $<32$ weeks' gestation with respiratory distress syndrome.

In our study, we found a low incidence of SNIPPV failure (14.1\%), comparable to a previous study by Salvo et al. [15], who reported that the incidence of failure for SNIPPV was 10 of 62 newborns (16\%). On the other hand, Kugelman et al. [16] found that the intubation rate in the SNIPPV group as a mode of primary respiratory support was $25 \%$. This may be related to a lower threshold for intubation. Another factor that may have contributed to lower failure in NIV support in our patients is use of prenatal glucocorticoid prophylaxis $(75.34 \%$ for successful group), known to be effective for lung immaturity.

The SNIPPV has theoretical benefits through the intermittent increase in pressure enhancing tidal volume (VT), minute ventilation, and MAP, resulting in better alveolar recruitment and gas exchange [17]. The SNIPPV improves ventilation by increasing VT [18], decreasing respiratory effort and improving oxygen saturation [19]. These mechanisms of action probably account for the higher success of the early SNIPPV strategy observed in our study. Comparison of the two groups found multiple significantly different characteristics. However, these can only be called associations and are not independent predictors.

Both gestational age and birth weight demonstrated a statistically significant difference between the two groups, which is an expected finding and may be related to a more severe presentation of RDS. However, neither of these proved to be independent predictors with multivariate logistic regression. Similarly, Nesbitt et al. [20], who investigated potential predictors for a successful trial of NIV following unplanned extubation, demonstrated that there was no significant predictive value of gestational age or birth weight. The fact that there were no significant differences for gender is consistent with previous findings [21].

Antenatal administration of corticosteroid therapy has been recommended in pregnancies with threatened preterm labor before 34 weeks' gestation where active care of the newborn is anticipated [18, 22]. Initial results showed a statistically significant difference with an increased rate of antenatal steroid use in the group with successful SNIPPV; this was presumed to be an association through amelioration of the course of RDS. However, multivariate logistic regression has demonstrated that antenatal steroid use in our patients was an independent predictor of success of SNIPPV.
The 5-minute Apgar score, and even more importantly, a change in the score between $1 \mathrm{~min}$ and $5 \mathrm{~min}$, is a useful index of the neonate's response to resuscitative efforts [23]. In our series Apgar scores at 5 min were significantly lower in the failed SNIPPV group than the successful one. Chambliss et al. [24] reported a higher risk of development of RDS in newborns with a 5-minute Apgar score of 7 . They concluded that the 5-minute score with the need for ongoing resuscitation may be a marker of lung immaturity or lung disease in that group of patients. Alternatively, the higher rate of SNIPPV failure in these patients can also be attributed to birth hypoxia leading to decreased central respiratory drive and therefore failed weaning [25].

In the present study we found that preterm infants belonging to the SNIPPV failure group had more severe RD than the successful group, and also had more severe grades of RDS with statistically significant differences. We used the Downes score for assessment of RD, and our findings are in agreement with Rusmawati et al. [26], who concluded that the Downes score can be used as a clinical diagnostic means for assessing hypoxemia in neonates with RD with $88 \%$ sensitivity (95\% Cl: $79-99)$, and $81 \%$ specificity $(95 \% \mathrm{Cl}$ : 70-91). Despite the fact that both were significant associations, only grade of RDS proved to be a significant independent predictor according to the multivariate analysis. A logical explanation could be that the grade of RDS is the determinant of the degree of RD, rendering the latter a dependent variable whilst the former is independent. Nicolini et al. [27] demonstrated similar findings in adults with community acquired pneumonia where the severity of lung involvement via X-ray findings was a significant predictor factor for NIV failure.

Our results show significantly shorter duration of oxygenation and hospital stay in the successful non-invasive group compared to neonates in the other one. Once again, this is an association in that NIV as a primary intervention in preterm neonates with RDS has been shown to be associated with reduction of length of hospital stay and decreased need of endotracheal tube ventilation [15].

It has also been demonstrated in our study the failed SNIPPV group had a significantly lower arterial $\mathrm{PaO}_{2}$ and $\mathrm{SpO}_{2}$ compared to the success group. Previous studies have suggested that hyperoxia, defined as a $\mathrm{pO}_{2}>80 \mathrm{~mm} \mathrm{Hg}$, causes oxidative stress, inflammation and bronchopulmonary dysplasia in premature infants due to the deficiency of the antioxidative system [28], and thus accounts for the association of hyperoxia with NIV failure. This was not the case here, and these findings do not have a cause-effect relationship since they may be the result of a more severe illness and multivar- 
iate analysis did not identify them as predictors. This also applies to the fact that neonates failing SNIPPV had a longer duration of ventilation support, possibly related to cumulative increased oxygen therapy, bouts of hypoxia or increased oxygen requirements due to more severe respiratory failure associated with an inability to protect the airway.

Our shorter duration of SNIPPV in successfully weaned neonates is promising. SNIPPV used as primary respiratory support in the treatment of RDS of very low birth weight infants has been demonstrated in various other studies to also be feasible and effective, with a brief duration requirement of respiratory support, with a median duration for SNIPPV of 89 h [15]. Similarly, Ramanathan et al. [29] reported significantly shorter duration of ventilation in the SNIPPV group.

A possible explanation was provided by Laughon et al. [30], who reported that $44 \%$ of 1340 infants had persistent oxygen requirements that averaged between $40 \%$ and $50 \%$ for the first 2 weeks of life, and $67 \%$ of this population developed BPD. By contrast, of the $19 \%$ of infants who had minimal oxygen needs for 2 weeks, only $17 \%$ developed BPD. This can be explained by the fact that during SNIPPV, the hypopharyngeal concentration of oxygen is lower due to mixing with room air during spontaneous breathing, which may also indirectly decrease the exposure to high oxygen concentration. A significant reduction in BPD has been reported when early SNIPPV is used for management of RDS [8]. Bhandari et al. [31] reported that use of SNIPPV was associated with decreased $\mathrm{BPD}$, death, and neurodevelopmental impairment compared with infants managed on NCPAP.

Although various ventilatory settings were found to be significantly different between the successful and failed SNIPPV groups, the only factor that was found to be a statistically significant predictor was mean airway pressure (MAP). Muñoz-Bonet et al. [32] also reported similar results; they found that MAP and $\mathrm{FiO}_{2}$ could predict failure of NIV when values exceeded $>11.5$ and 0.6 , respectively.

Although we have three statistically significant predictors by multivariate logistic regression, the predictor with the largest OR is grade of RDS, followed by MAP and antenatal steroid use having the smallest effect with an OR of 1.09. A study in older children with respiratory failure also identified two comparable criteria as predictors for NIV success: MAP change and baseline degree of illness [33]. A possible limitation of our study is that the failure group was small, with only 12 patients, and therefore did not allow for extraction of other potential predictors.

Other predictive factors that have been reported in the literature for pediatric NIV but were not included in this study are a higher $\mathrm{PaO}_{2} / \mathrm{FiO}_{2}$ be- fore NIV [33], hemodynamic response to NIV for success and a higher $\mathrm{PaCO}_{2}$ for failure [34], low $\mathrm{pH}$ immediately after initiation of NIV as a predictor of failure [35], respiratory rate prior to NIV (James et al.) and the number of failing organs [36].

In conclusion, although we found multiple associations with failure of SNIPPV, the predictors were grade of RDS, MAP and antenatal steroid use. Predictors of noninvasive ventilation failure might be used to guide decisions regarding intubation.

\section{Conflict of interest}

The authors declare no conflict of interest.

\section{References}

1. Edwards MO, Kotecha SJ, Kotecha S. Respiratory distress of the term newborn infant. Pediatric Respir Rev 2013; 14: 29-36.

2. Verder H. Nasal CPAP has become an indispensable part of the primary treatment of newborns with respiratory distress syndrome. Acta Paediatr 2007; 96: 482-4.

3. Khalaf MN, Brodsky N, Hurley J, Bhandari V. A prospective randomized, controlled trial comparing synchronized nasal intermittent positive pressure ventilation versus nasal continuous positive airway pressure as modes of extubation. Pediatrics 2001; 108: 13-7.

4. Ramanathan R, Sardesai S. Lung protective ventilatory strategies in very low birth weight infants. J Perinatol 2012; 28: 41-6.

5. Moretti C, Giannini L, Fassi C, Gizzi C, Papoff P, Colarizi P. Nasal flow synchronized intermittent positive pressure ventilation to facilitate weaning in very low-birthweight infants: unmasked randomized controlled trial. Pediatr Int 2008; 50: 85-91.

6. Li W, Long C, Zhangxue $\mathrm{H}$, et al. NIPPV versus nasal CPAP for preterm infants with RDS: a meta-analysis and up-date. Pediatr Pulmonol 2015; 50: 402-9.

7. Kiciman NM, Andréasson B, Bernstein G, et al. Thoracoabdominal motion in newborns during ventilation delivered by endotracheal tube or nasal prongs. Pediatr Pulmonol 1998; 25: 175-81.

8. Friedlich P, Lecart C, Posen R, Ramicone E, Chan L, Ramanathan R. A randomized trial of nasopharyngeal-synchronized intermittent mandatory ventilation versus nasopharyngeal continuous positive airway pressure in very low birth weight infants after extubation. J Perinatol 1999; 19: 413-8.

9. Meneses J, Bhandari V, Alves JG, Herrmann D. Noninvasive ventilation for RDS: a randomized controlled trial. Pediatrics 2011; 127: 300-7.

10. Aghai ZH, Saslow JG, Nakhla T, et al. SNIPPV decreases work of breathing (WOB) in premature infants with RDS compared to NCPAP. Pediatr Pulmonol 2006; 41: 875-81.

11. Downes JJ, Vidyasagar D, Boggs TR, Morrow GM. Respiratory distress syndrome of newborn infants. I. New clinical scoring system (RDS score) with acid--base and blood-gas correlations. Clin Pediatr 1970; 9: 325-31.

12. Arthur R. The neonatal chest X-ray. Paediatr Respir Rev 2001; 2: 311-23.

13. Salvo V, Lista G, Lupo E, et al. Noninvasive ventilation strategies for early treatment of RDS in preterm infants: an RCT. Pediatrics 2015; 135: 444-51. 
14. Garg S, Sinha S. Non-invasive respiratory support in preterm infants: do we need more evidence? Infant 2014; 10: 44-8.

15. Salvo V, Lista G, Lupo $E$, et al. Comparison of three non-invasive ventilation strategies (NSIPPV/BiPAP/NCPAP) for RDS in VLBW infants. J Matern Fetal Neonatal Med 2017; 1-7. doi: 10.1080/14767058.2017.1357693.

16. Kugelman A, Feferkorn I, Riskin A, Chistyakov I, Kaufman B, Bader D. Nasal intermittent mandatory ventilation versus nasal continuous positive airway pressure for respiratory distress syndrome: a randomized, controlled, prospective study. J Pediatr 2007; 150: 521-6.

17. Roberts CT, Davis PG, Owen LS. Neonatal non-invasive respiratory support: synchronised NIPPV, non-synchronised NIPPV or bi-level CPAP: what is the evidence in 2013? Neonatology 2013; 104: 203-9.

18. Owen LS, Morley CJ, Dawson JA, Davis PG. Effects of non synchronised nasal intermittent positive pressure ventilation on spontaneous breathing in preterm infants. Arch Dis Childhood Fetal Neonatal Ed 2011; 2: 422-8.

19. Chang HY, Claure N, D'ugard C, Torres J, Nwajei P, Bancalari E. Effects of synchronization during nasal ventilation in clinically stable preterm infants. Pediatr Res 2011; 69: 84-9.

20. Nesbitt G, Guy KJ, König K. Unplanned extubation and subsequent trial of noninvasive ventilation in the neonatal intensive care unit. Am J Perinatol 2015; 32: 1059-63.

21. Ramos-Navarro C, Sanchez-Luna M, Sanz-López E, Maderuelo-Rodriguez E, Zamora-Flores E. Effectiveness of synchronized noninvasive ventilation to prevent intubation in preterm infants. Am J Perinatol Rep 2016; 6: 264-71.

22. Manktelow BN, Lal MK, Field DJ, Sinha SK. Antenatal corticosteroids and neonatal outcomes according to gestational age: a cohort study. Arch Dis Child Fetal Neonatal Ed 2010; 95: 95-8.

23. American Academy of Pediatrics and American Heart Association. Textbook of Neonatal Resuscitation. $6^{\text {th }}$ ed. Elk Grove Village, IL: American Academy of Pediatrics and American Heart Association 2011.

24. Chambliss L, Bay R. The predictive value of a 5-minute Apgar for developing respiratory distress syndrome. Obstetr Gynecol 2005; 105: 1S.

25. Badiee Z, Nekooie B, Mohammadizadeh M. Noninvasive positive pressure ventilation or conventional mechanical ventilation for neonatal continuous positive airway pressure failure. Int J Prev Med 2014; 5: 1045-53.

26. Rusmawati A, Haksari EL, Naning R. Downes score as a clinical assessment for hypoxemia in neonates with respiratory distress. Paediatr Indones 2008; 48: 342-5.

27. Nicolini A, Piroddi IM, Barlascini C, Senarega R. Predictors of non-invasive ventilation failure in severe respiratory failure due to community acquired pneumonia. Tanaffos 2014; 13: 20-8.

28. Teixeira AB, Xavier CC, Lamounier JA, Tavares EC. Hyperopia and greater risk for bronchopulmonary dysplasia in preterm infants. Rev Paul Pediatr 2007; 25: 47-52.

29. Ramanathan R, Sekar KC, Rasmussen M, Bhatia J, Soll RF. Nasal intermittent positive ventilation after surfactant pressure treatment for respiratory distress syndrome in preterm infants <30 weeks' gestation: a randomized, controlled trial. J Perinatol 2012; 32: 336-43.

30. Laughon M, Allred EN, Bose C, et al. Patterns of respiratory disease during the first 2 postnatal weeks in extremely premature infants. Pediatrics 2009; 123: 1124-31.
31. Bhandari V, Gavino RG, Nedrelow JH, et al. A randomized controlled trial of synchronized nasal intermittent positive pressure ventilation in RDS. J Perinatol 2007; 27: 697-703.

32. Muñoz-Bonet J, Flor-Macián EM, Brines J, et al. Predictive factors for the outcome of noninvasive ventilation in pediatric acute respiratory failure. Pediatr Crit Care Med 2010; 11: 675-80.

33. Elsamahy $M$, Abdelmonem $M$, Ibrahim $H$, Eldin $M$, Allam A. Success or failure of non-invasive positive pressure ventilation in children with acute respiratory failure. Could it be predicted? Arch Med Sci Civil Dis 2017; 2: 113-20.

34. Bakalli I, Celaj E, Simaku A, Kola E, Sallabanda S. Predictors of noninvasive ventilation success in children with acute respiratory failure. Intensive Care Med 2015; 41 : 950-1.

35. Dohna-Schwake C, Stehling F, Tschiedel E, Wallot M, Mellies U. Non-invasive ventilation on a pediatric intensive care unit: feasibility, efficacy, and predictors of success. Pediatr Pulmonol 2011; 46: 1114-20.

36. Piastra M, De Luca D, Marzano L, et al. The number of failing organs predicts non-invasive ventilation failure in children with ALI/ARDS. Intensive Care Med 2011; 37: 1510-6. 